\title{
Antimicrobial use and farmers' attitude toward mastitis treatment on dairy farms with automatic or conventional milking systems
}

\author{
Z. Deng, ${ }^{1 *}$ ๑ T. J. G. M. Lam, ${ }^{1,2}$ H. Hogeveen, ${ }^{1,3} \odot$ M. Spaninks, ${ }^{1}$ N. Heij, ${ }^{1}$ M. Postema, ${ }^{1}$ T. van Werven, ${ }^{1,4} \odot$ \\ and G. Koop ${ }^{1}$ \\ ${ }^{1}$ Department of Population Health Sciences, Utrecht University, Utrecht $3584 \mathrm{CL}$, the Netherlands \\ ${ }^{2}$ GD Animal Health, 7400 AA Deventer, the Netherlands \\ ${ }^{3}$ Chair Group Business Economics, Wageningen University and Research, $6700 \mathrm{EW}$ Wageningen, the Netherlands \\ ${ }^{4}$ University Farm Animal Practice, Harmelen 3481 LZ, the Netherlands
}

\begin{abstract}
Mastitis is one of the major causes for antimicrobial use on dairy cattle farms. On farms with an automatic milking system (AMS), diagnostics differ from those with a conventional milking system (CMS), with potentially a different attitude toward mastitis treatment. This may result in differences in antimicrobial usage (AMU) between these 2 types of farms. The aims of this study were (1) to compare AMU between AMS and CMS farms, (2) to identify variables associated with AMU in both types of herds, and (3) to describe the distribution of mastitis-causing pathogens and their antimicrobial resistance patterns. Data on AMU was collected for 42 AMS and 254 CMS farms in the Netherlands and was expressed as animal-defined daily dose (ADDD). The ADDD variables were total usage $\left(\mathrm{ADDD}_{\text {TотAL }}\right)$, intramammary usage during lactation $\left(\mathrm{ADDD}_{\mathrm{IMM}}\right)$, usage for dry cow therapy $\left(\mathrm{ADDD}_{\mathrm{DCT}}\right)$, and usage by injection $\left(\mathrm{ADDD}_{\mathrm{INJ}}\right)$. Eighteen $\mathrm{AMS}$ farms and $24 \mathrm{CMS}$ farms participated in a survey on factors potentially related to AMU. These farmers collected 5 quarter milk samples from quarters with clinical mastitis or high somatic cell count, which were subjected to bacteriological culture and antimicrobial susceptibility testing. In addition, routinely collected udder health data of these farms were used in the analysis. Nonlinear principal component analysis (NLPCA) was used to explore associations between AMU, udder health, and questionnaire variables. The $\mathrm{ADDD}_{\text {TотAL }}$ and $\mathrm{ADDD}_{\mathrm{DCT}}$ were comparable between AMS and CMS farms, whereas $\mathrm{ADDD}_{\text {IMM }}$ tended to be lower and $\mathrm{ADDD}_{\text {INJ }}$ higher on AMS farms than on CMS farms. The NLPCA yielded 3 principal components (PC) that explained $48 \%$ of
\end{abstract}

\footnotetext{
Received November 25, 2019

Accepted March 18, 2020.

*Corresponding author: zhaoju.deng2014@gmail.com
}

the variation in all these variables. The AMS farms were not distinguished from CMS farms in the principal component space. The $3 \mathrm{PC}$ represented different aspects of udder health, $\mathrm{ADDD}_{\text {TотAL }}$, and treatment strategy. Differences in treatment strategy were unrelated to total antimicrobial usage or overall udder health. The distribution of mastitis-causing pathogens and their antimicrobial resistance were comparable between AMS and CMS farms. In conclusion, our study shows that AMU on AMS farms was similar to that of CMS farms, but AMS farmers tend to apply more injectable and fewer intramammary treatments during lactation than CMS farmers. Across both farm types, farmers' attitudes toward udder health in general and toward mastitis treatment are associated with AMU. Key words: automatic milking system, antimicrobial usage, attitude, udder health

\section{INTRODUCTION}

Antimicrobial usage (AMU) in food-producing animals is one of the drivers of antimicrobial resistance (AMR; Van Boeckel et al., 2014; Tang et al., 2017). For that reason, various policies to reduce AMU in livestock have been proposed and implemented (e.g., Mathew et al., 2007; Levy, 2014; Speksnijder et al., 2015). Most AMU in dairy cattle is related to udder health (Mitchell et al., 1998). In the Netherlands, for instance, $22 \%$ of AMU on dairy farms was related to clinical mastitis (CM) and $44 \%$ to dry cow treatment (Kuipers et al., 2016), and comparable proportions have been described in Canada (Nobrega et al., 2018) and Ireland (More et al., 2017). Controlling AMU is important because, for instance, the emergence of AMR in Staphylococcus aureus has been reported to be associated with herdlevel use of certain antimicrobials (Saini et al., 2012), as was the prevalence of multi-drug-resistant NAS isolates (Nobrega et al., 2018).

Diagnosis is an important first step in the decisionmaking process that leads to use of antimicrobials re- 
lated to mastitis. On farms with an automatic milking system (AMS), mastitis is diagnosed differently than on farms with a conventional milking system (CMS), because in AMS farms, mastitis diagnostics rely primarily on sensors (Viguier et al., 2009; Jacobs and Siegford, 2012), which may affect AMU. For instance, the use of electrical conductivity for mastitis detection has been found to be positively related to AMU for treatment of both subclinical mastitis (SCM; Biggadike et al., 2002) and CM (Kayitsinga et al., 2017). Later in the mastitis treatment process, AMS farmers may also differ from CMS farmers in terms of attitude toward treatment for mastitis. Vilar et al. (2018) reported that Finnish AMS farmers tend to more frequently use blanket dry cow therapy (DCT) than CMS farmers. Differences in diagnostics and in attitude toward treatment of mastitis may result in differences in AMU between AMS and CMS farms. In addition, the milking system may also affect udder health in general (Lam et al., 2013; Nor et al., 2014; Deng et al., 2019) and the distribution of mastitis-causing pathogens in a herd. It is important to understand the drivers of AMU and to know how AMS farmers differ in their approach to mastitis treatment and AMU from CMS farmers in order to tailor programs to further reduce AMU to prevent further development of AMR in dairy herds. To our knowledge, no studies have compared AMU between AMS and CMS farms and investigated the diagnostic and treatment approaches of the farmers associated with AMU. In this study, we use AMU data that has been recorded for a large number of AMS and CMS farms as well as data from telephone interviews to obtain more in-depth information on potential drivers of AMU in a selection of these farms. Given the large number of variables obtained in this approach, we use principal component analysis (PCA) to analyze our data. The PCA technique can be used to reduce the dimensions of data and to identify structure in the relationships between variables. As heterogeneous variable types, such as categorical and numerical variables, and nonlinear relationships among variables are common in questionnaire data, we employed nonlinear PCA (NLPCA), in which categorical variables are transformed into numeric quantifications. After this quantification, the subsequent analysis steps are the same as in linear PCA (Linting et al., 2007).

The aims of this study were (1) to compare AMU between AMS and CMS farms, (2) to determine variables associated with AMU in both types of herds, including the farmers' attitudes toward mastitis detection and treatment, and (3) to describe the distribution of mastitis-causing pathogens and their antimicrobial resistance patterns in both types of herds.

\section{MATERIALS AND METHODS}

\section{Study Outline}

For this study, we used routinely collected AMU data on all 296 dairy farms (42 AMS and 254 CMS farms) served by the University Farm Animal Practice (Harmelen, the Netherlands) that gave written consent to use their data. All 42 AMS farmers and an equal number of randomly selected CMS farmers were invited by email to participate in a more detailed study. This resulted in a subset of 42 farmers (18 AMS and 24 CMS farms) who were willing to participate, from whom we also collected udder health data and to whom we administered a telephone interview about their approach toward diagnosis and treatment of mastitis. Farmers who participated in the interview were also invited to submit 5 milk samples from CM cases (if needed, supplemented with SCM cases) to determine mastitiscausing pathogens and the corresponding AMR profiles.

\section{Antimicrobial Usage Data}

The AMU data of 42 AMS farms and 254 CMS farms served by the University Farm Animal Practice were used for analysis of the AMU data that were extracted from the Dutch national database for registration of AMU in cattle (Medirund; https://www.medirund .nl/menu/Home). The AMU data were expressed as animal-defined daily dosage (ADDD), as described by Gonggrijp et al. (2016), and included total usage (ADDD TотAL $_{\text {, }}$, intramammary usage during lactation $\left(\mathbf{A D D D}_{\mathrm{IMM}}\right)$, usage for dry cow therapy $\left(\mathbf{A D D D}_{\mathbf{D C T}}\right)$, and usage by injection $\left(\mathbf{A D D D}_{\text {INJ }}\right)$. No information on the indications for antimicrobial use were available in the data set; thus, we could not determine whether $\mathrm{ADDD}_{\text {INJ }}$ was associated with mastitis treatment. In addition to the comparison of the absolute values of AMU variables for each application route, the proportion for each application route of $\mathrm{ADDD}_{\text {TотAL }}$ was also compared between AMS and CMS farms. The median of all AMU variables in the small data set were compared with the corresponding median of the same AMU variables in the large data set on farms with the same milking system. The median of the same AMU variables in both data sets were compared between AMS and CMS farms using the Wilcoxon rank-sum test.

\section{Questionnaire Data}

Questionnaire items were designed for this study and were not based on a pre-existing theoretical framework. During telephone interviews, farmers were asked open 
questions, or closed questions that were followed up by open questions, by a trained master's student. The 42 farmers (18 AMS and $24 \mathrm{CMS}$ ) were questioned on their definition of mastitis, the methods they used to diagnose mastitis, their approach toward treatment of clinical or subclinical mastitis, and their approach toward antimicrobial use. The questionnaire was pretested in 3 farms that were not otherwise involved in the research, and subsequently several questions were changed to improve understanding by the farmers. The questionnaire was administered in Dutch and consisted of 31 questions, of which 19 were open questions, and the interviews were recorded. The responses were categorized into inductively created themes after finalization of the interviews to accommodate answer categories given by the farmers, as follows: one of the authors translated the questionnaire into English, and this translation was reviewed by another author of the paper. Then, for open questions, answer categories were designed based on the various answers given by the farmers. This recoding of the open questions was checked by a second author independently, and, in case of disagreement, the coding of the answers was discussed among the authors. Variables with more than 8 missing records were presented in the descriptive statistics but were excluded from further statistical analyses. Fisher's exact test was used to compare the distribution of answer categories in the questionnaire results between the 2 types of farms.

\section{Udder Health Data}

For the 42 farms that participated in the telephone interview, during the year preceding the administration of the questionnaire (November 2016 to November 2017) rolling yearly averages were collected for DHI variables related to udder health and other farm characteristics, and included the following: total number of cows, annual geometric mean bulk milk SCC, annual geometric mean of herd SCC, average percentage of high SCC cases, average percentage of new high SCC cases, average percentage of new high SCC cases in the dry period, and average percentage of cured high SCC cases during the dry period. The threshold for high SCC was $\geq 250,000$ cells $/ \mathrm{mL}$ for multiparous cows and $\geq 150,000$ cells $/ \mathrm{mL}$ for heifers (de Haas et al., 2008). The percentage of new high SCC cases during the dry period was calculated as the percentage of cows with a high SCC at the first milk recording after calving out of the total number of cows with a low SCC at drying off. The percentage of cured cases during the dry period was calculated as the percentage of cows with a low SCC at the first recording after calving out of the number of cows with a high SCC at the last recording before drying off (Vanhoudt et al., 2018).

\section{Milk Samples}

Around the time of the interview (November 2017), the farmers were provided with 5 labeled milk tubes and were invited to collect quarter milk samples of cases of CM from 5 different cows until January 2018. If fewer than 5 cases of $\mathrm{CM}$ were seen in this time period, the farmer could supplement these by samples of SCM cases (according to the farmer's own definition of SCM) to a total of 5 quarter milk samples. The farmers were asked to store the milk samples at $-20^{\circ} \mathrm{C}$ until all 5 samples were collected. They filled out a form for each milk sample to record sampling date, cow identification number, parity, most recent calving date, affected quarter, clinical signs, and whether the cow had received treatment.

\section{Bacteriological Culture and Antimicrobial Resistance Testing}

Milk samples were subjected to bacteriological culture according to NMC guidelines (NMC, 2017). In brief, $10 \mu \mathrm{L}$ of milk was plated on a blood agar plate and incubated at $37^{\circ} \mathrm{C}$. Results were read at approximately 24 and $48 \mathrm{~h}$ of incubation. Bacteria were identified with MALDI-TOF MS using the MALDI Biotyper Microflex LT (Bruker Daltonics GmbH, Bremen, Germany; Barreiro et al., 2010). Isolates with identification score $\geq 2.0$ were considered successfully identified. Culture results were recorded as culture negative if no bacteria were cultured on the blood agar plate and as culture positive if 1 or 2 morphologically different colony types with $\geq 1$ colonies were found. Samples yielding $\geq 3$ phenotypically distinct colonies were considered as contaminated. Of all available Staphylococcus aureus, Streptococcus uberis, Streptococcus dysgalactiae, and NAS isolates from non-contaminated samples, antimicrobial susceptibility was tested with the Micronaut-S Mastitis 3 plate (Merlin Diagnostics, Berlin, Germany). Inoculum preparation, broth composition, and incubation conditions were performed according to the manufacturer's guidelines. The antimicrobials tested were amoxicillin/clavulanic acid, ampicillin, cefazolin, cefoperazone, cefquinome, erythromycin, kanamycin/ cephalexin, marbofloxacin, oxacillin, penicillin G, and pirlimycin. The plates were read after incubation with a photometer (Skan, Merlin Diagnostics). We used Staph. aureus ATCC 29213 as quality-control strain. Human breakpoints for each antimicrobial were used as clinical breakpoints in antimicrobial resistance tests. 


\section{Statistical Analysis}

The ADDD for various purposes, farm characteristics, and udder health variables were compared between AMS and CMS farms, and differences were tested using the Wilcoxon rank-sum test for variables with a non-normal distribution or Student's $t$-test for normally distributed variables (normality was checked by visual inspection of the quantile-quantile plot for each variable). To explore the possible factors associated with AMU variables, we performed NLPCA on the questionnaire variables, udder health data, and the AMU data using the princals function from Gifi package version 0.3-7 (Mair et al., 2017; https://rdrr.io/ rforge/Gifi/) in R version 3.5.1 (R Core Team, 2018). We tested NLPCA with 3-, 4-, and 5-dimensional solutions, and the number of principal components (PC) was determined by scree plot and the interpretability of the PC (Linting et al., 2007). Of all 42 farms, 3 had a missing value in 1 variable, and 1 had missing values in 9 variables. These 12 missing values were imputed as the mean of all other farms for the same variable, to enable us to run the NLPCA using all farms and variables.

\section{RESULTS}

\section{Antimicrobial Usage and Udder Health}

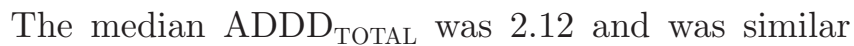
between AMS and CMS farms (Table 1). On average, $39 \%$ of the $\mathrm{ADDD}_{\text {TOTAL }}$ could be attributed to $\mathrm{DCT}$, and this too was very similar between the 2 farm types. The $\mathrm{ADDD}_{\text {IMm }}$ tended to be lower, whereas the $\mathrm{ADDD}_{\text {INJ }}$ tended to be higher on AMS farms compared with CMS farms. The average proportion of $\mathrm{ADDD}_{\text {IMM }}$ of $\mathrm{ADDD}_{\text {TотаL }}$ was significantly lower $(P<0.05)$ on AMS farms, and the average proportion of $\mathrm{ADDD}_{\text {INJ }}$ of $\mathrm{ADDD}_{\text {TотаL }}$ was significantly higher $(P<0.05)$ on AMS farms compared with CMS farms. The subset of 42 farms that participated in the questionnaire had higher AMU than the non-participating farms in each type of farm, but the comparison between AMS and CMS farms in AMU gave similar results to those found in the larger data set (Table 2; none of the comparisons was significant by Wilcoxon rank-sum test). The AMS herds were significantly $(P<0.05)$ larger than CMS herds, and AMS herds tended to have a higher average 305-d milk yield (Table 2). Udder health variables were similar between AMS and CMS farms, except for the proportion new high SCC $(P=0.06)$ and the proportion of new high SCC during the dry period $(P=0.10)$, which tended to be slightly higher in AMS herds (Table $2)$.

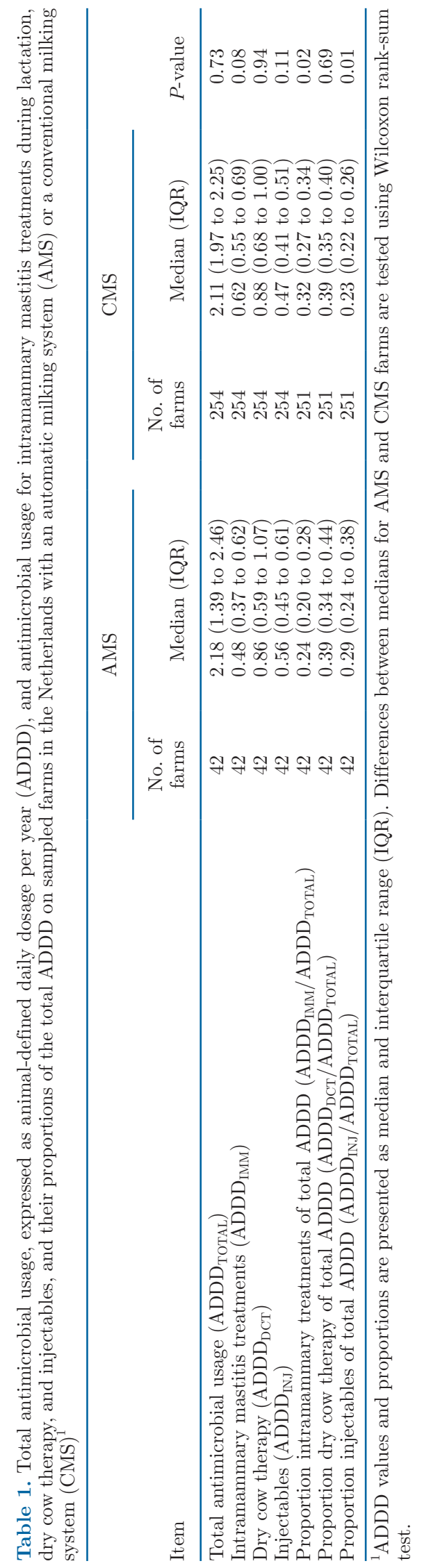


Deng et al.: ANTIMICROBIAL USE AND FARMERS' ATTITUDES

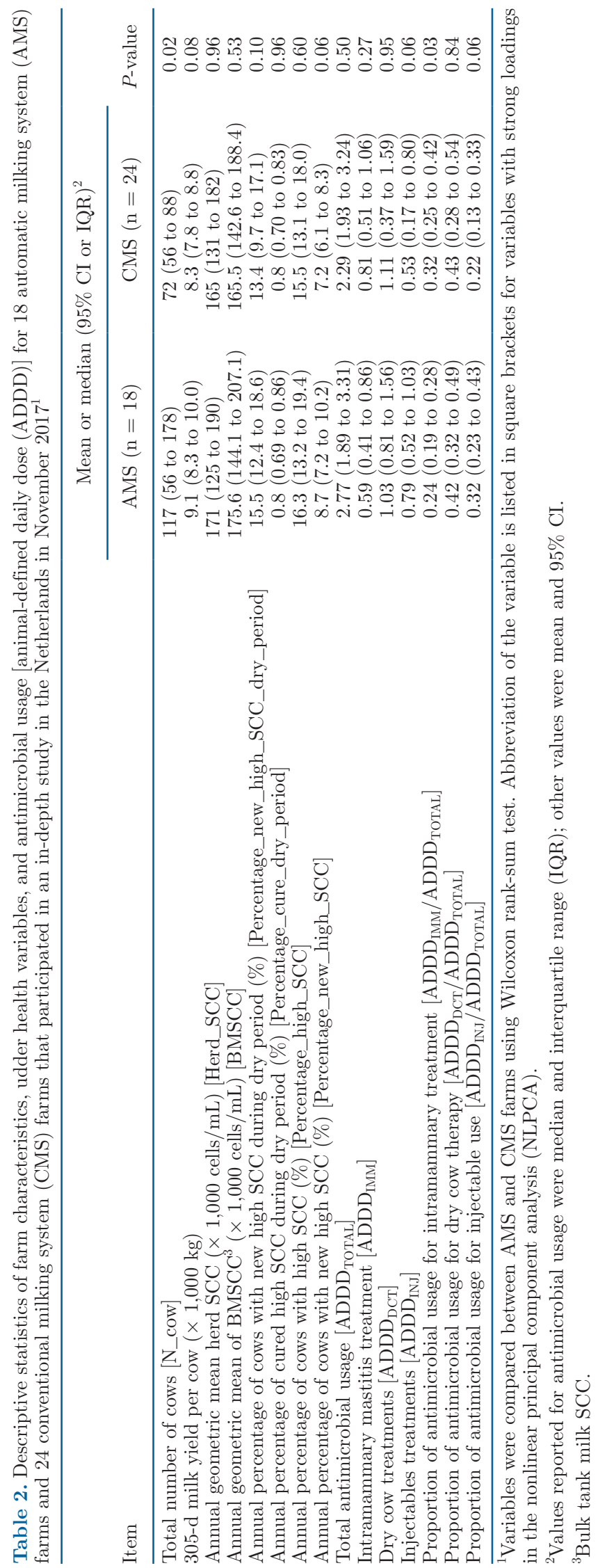

\section{Questionnaire}

The first open question was about what farmers consider to be "clinical mastitis." Some farmers indicated "when a cow has abnormal milk," but most farmers added that the udder should also show symptoms, such as clots in milk or abnormalities in the udder, or that the cow should have systemic symptoms of disease. Interestingly, AMS farmers significantly $(P<0.05)$ more frequently mentioned systemic symptoms, whereas CMS farmers more often talked about symptoms of the udder (Table 3). In a follow-up question, farmers were asked about what grades of mastitis they discern. Most farmers distinguished mild and severe cases. The interviewer then asked about the farmer's definition of mild and severe. Some farmers grouped cows with an abnormal udder under mild mastitis, whereas others categorized this as severe. About one-third of the farmers mentioned the 3 grades of mastitis as defined by Pinzón-Sánchez and Ruegg (2011). The approach toward treatment was very similar between AMS and CMS farmers. The majority of farmers do not treat all CM cases with antimicrobials but select cows for treatment based on severity of the mastitis case, or treat with antimicrobials only after a non-antimicrobial treatment failed. Around $45 \%$ of the farmers reported never treating high-SCC cows with antimicrobials. Bacteriological culture is sometimes performed by most farmers, mostly to better understand the mastitis problem on the farm or to tailor the treatment for a specific cow. The majority of farmers reported following up on treatments, which most CMS farmers based on clinical inspections of the cow or the milk, whereas AMS farmers primarily used milk quality data such as electrical conductivity or SCC.

\section{Bacteriological Culture and Antimicrobial Resistance}

The CMS farmers submitted more milk samples per farm to us than the AMS farmers did (on average, 3.8 and 3.4 samples per farm, respectively). Of the 42 participating farms, 3 AMS farms and 1 CMS farm did not provide any milk samples. Table 4 shows that Staph. aureus, Strep. uberis, Escherichia coli, NAS (Staphylococcus chromogenes, Staphylococcus epidermidis, Staphylococcus equorum, Staphylococcus haemolyticus, Staphylococcus hominis, Staphylococcus sciuri, Staphylococcus simulans, Staphylococcus succinus, Staphylococcus vitulinus, and Staphylococcus xylosus), and Strep. dysgalactiae were the most prevalent pathogens in these samples, and their distributions were similar in AMS and CMS farms. Most of the isolates were susceptible to the antimicrobials tested (Table 5). Most resistance was observed in Staphylococcus spp., but no significant 
Deng et al.: ANTIMICROBIAL USE AND FARMERS' ATTITUDES

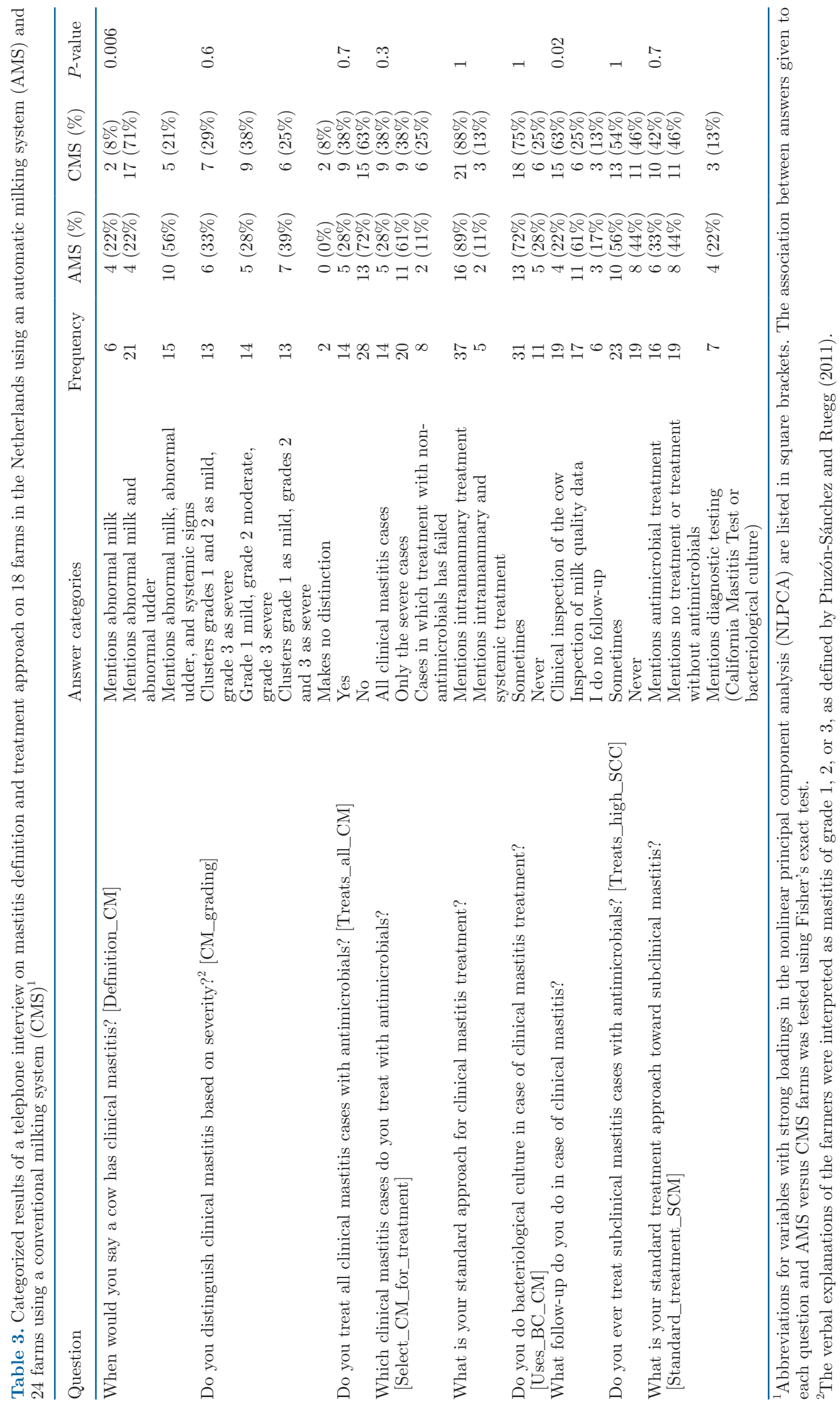


differences in the proportions of resistant isolates were seen between isolates from AMS and CMS farms.

\section{Nonlinear PCA}

The NLPCA with 3 dimensions explained, in total, $48 \%$ of the variation in AMU variables, udder health variables, questionnaire information, and other farm characteristics, such as herd size and milk yield. Figure 1 shows biplots of the variables that are most influential in the NLPCA and the location of the AMS and CMS farms in principal component space. Transformation plots, which are needed for the interpretation of these results and which show how the original variables were transformed into numerical variables, are shown in Figure 2 for variables with loadings $>0.30$ or $<-0.30$ in the NLPCA. The abbreviations used in the biplots are given in Table 2 and Table 3. Clearly, the 2 farm types could not be distinguished by the combination of the $3 \mathrm{PC}$, as their localizations in the graphs overlap. The first PC primarily distinguishes farms based on udder health and AMU variables. A high score on this PC represents poorer udder health, exemplified by high bulk milk SCC and more (new) high SCC, but less AMU. The $\mathrm{ADDD}_{\text {TOTAL }}$ and $\mathrm{ADDD}_{\mathrm{DCT}}$ both had negative loadings in this PC, suggesting that better udder health was associated with more AMU in general and less AMU at drying off. Farms scoring high on PC1 have farmers who are less inclined to treat clinical or subclinical mastitis with antimicrobials. The second PC had strong positive loadings for ADDD $_{\text {TOTAL }}$, $\mathrm{ADDD}_{\mathrm{DCT}}$, and $\mathrm{ADDD}_{\mathrm{IMM}}$, suggesting that this $\mathrm{PC}$ represents higher AMU in general. Interestingly, this was associated with low loadings for cure of high SCC in the dry period. Farmers scoring high on PC2 were more inclined to treat $\mathrm{CM}$ and SCM with antimicrobials. The third PC distinguishes farmers who tend to use antimicrobials at drying off (loading positive on this axis) versus during the lactation (loading negative on this axis): $\mathrm{ADDD}_{\mathrm{DCT}}$ and the proportion of $\mathrm{ADDD}_{\mathrm{DCT}}$ of $\mathrm{ADDD}_{\text {TOTAL }}$ loaded positively on this axis, whereas the proportion $\mathrm{ADDD}_{\text {IMM }}$ of $\mathrm{ADDD}_{\text {TотAL }}$ and variables indicating that farmers would treat all cases of $\mathrm{CM}$ and cases of SCM with antimicrobials had a negative loading on PC3.

\section{DISCUSSION}

In this study, we aimed to compare AMU between AMS and CMS farmers and to explore factors potentially associated with AMU. We found that AMS farmers tended to use fewer intramammary treatments and more injectables than did CMS farmers, but the total AMU was the same. Although AMS farmers more

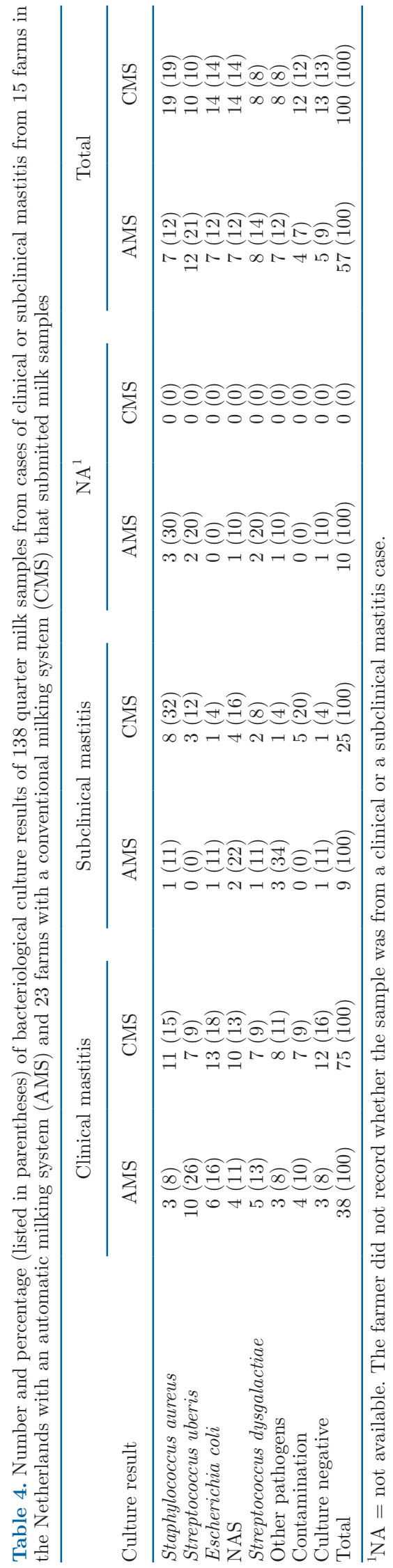




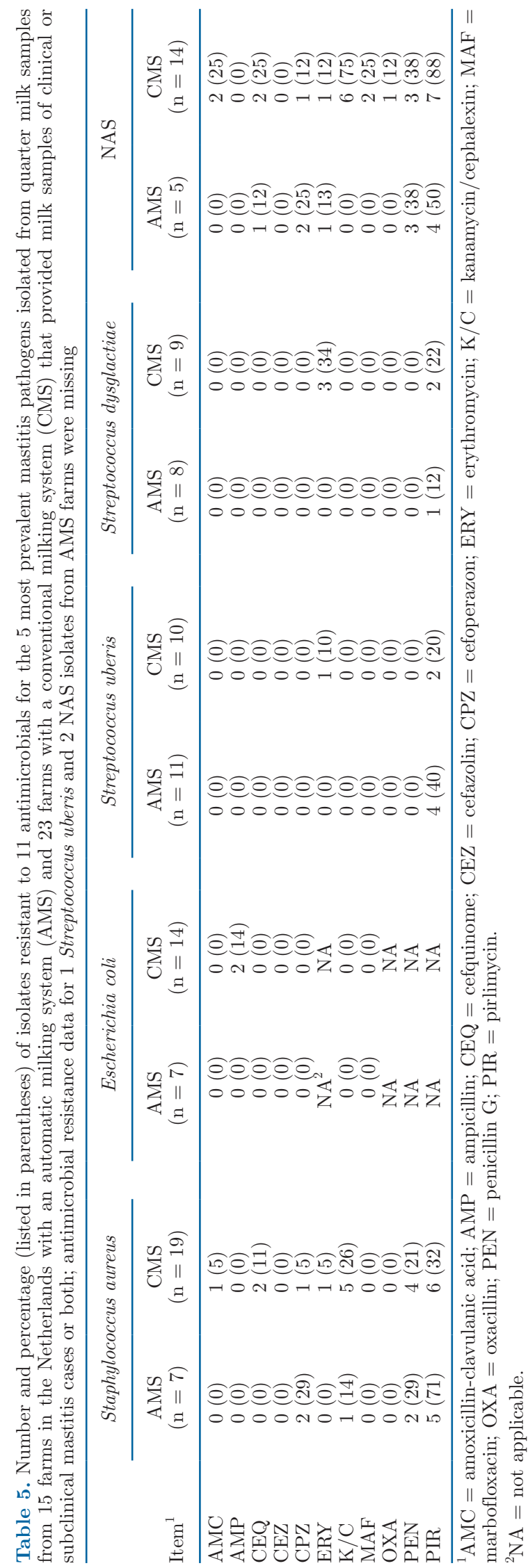

often mentioned severe symptoms than CMS farmers did when asked about their description of $\mathrm{CM}$, the 2 farm types could not be distinguished in an NLPCA based on their definitions of and treatment approaches toward mastitis and AMU.

\section{Antimicrobial Usage}

In comparison of AMU, we compared not only the absolute values of AMU variables but also the proportions of AMU for each specific purpose between AMS and CMS farms to identify the treatment strategies on these 2 different types of farms. The median ADDD and $\mathrm{ADDD}_{\mathrm{IMM}}$ in our study were comparable to the median usage of Dutch dairy farms, which were 2.1 and 0.5, respectively, in 2017 (SDa, 2018). However, $\mathrm{ADDD}_{\text {DCT }}$ in our sample (median: 0.88) was lower than the national median (1.1). The subset of farms that participated in the interviews had higher $\mathrm{ADDD}_{\text {TотAL }}$, but their $\mathrm{ADDD}_{\mathrm{DCT}}$ was in line with the national data. In terms of herd size, AMS farms were larger and CMS farms smaller than the Dutch average herd size (regardless of AMS or CMS) of 97 cows at the time of the study (Van der Peet et al., 2018). The udder health variables of these 42 herds were comparable to what was reported for Dutch dairy farms in previous work (Nor et al., 2014; Steeneveld et al., 2015). The average 305-d milk yield was higher in both farm types compared with what was previously reported by Steeneveld and Hogeveen (2015). Thus, the farms included in our study were reasonably representative of Dutch dairy farms using AMS and CMS.

Few studies have investigated differences in AMU between AMS and CMS herds. Vilar et al. (2018) reported that AMS farms were more likely to apply blanket DCT than CMS farms. Blanket DCT, however, is not allowed in the Netherlands (Scherpenzeel et al., 2016). Our study found that AMS farmers and CMS farmers used equal amounts of antimicrobials during the lactation and at drying off, but we found that AMS farmers used fewer intramammary treatments and more injectables. It should be noted, however, that the higher $\mathrm{ADDD}_{\text {INJ }}$ in AMS herds is not necessarily related to mastitis treatments. The injectables may also have been used for reasons other than udder health, which we could not evaluate because the indication for use of the antimicrobials is not recorded in the national antimicrobial registration system. The lower $\mathrm{ADDD}_{\text {IMM }}$ and higher $\mathrm{ADDD}_{\mathrm{INJ}}$ in AMS herds may be explained by the fact that it is simply more challenging to apply intramammary treatments outside of a milking parlor. In a conventional milking parlor, administering intramammary treatments is convenient and can be implemented easily in the daily milking routine. For farmers 


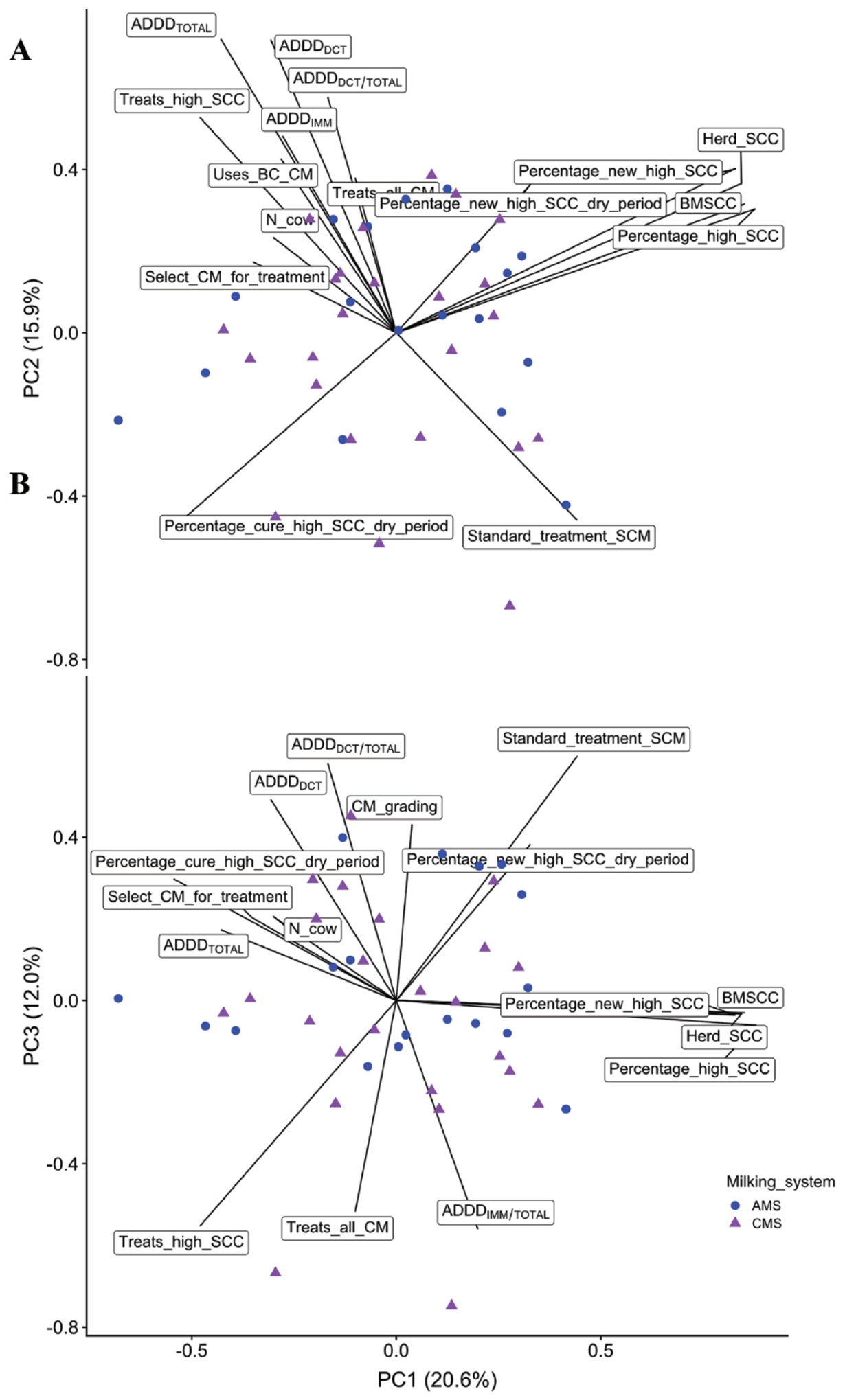

Figure 1. Biplots based on a nonlinear principal component analysis (NLPCA) of 18 farms in the Netherlands with an automatic milking system (AMS) and 24 farms with a conventional milking system (CMS). For all farms, questionnaire information, udder health data, and antimicrobial usage data were collected and analyzed via NLPCA. The biplots present the location of farms in the principal component (PC) space and the variance explained by each variable on the PC axes. Biplot of (A) the second against the first PC and (B) the third against the first PC. The loadings of variables with loadings $>0.30$ or $<-0.30$ are shown as lines. Object scores were scaled to 0.25 of the raw value and depicted as circles for AMS farms and as triangles for CMS farms. Explanations of variable abbreviations can be found in Tables 2 and 3. 

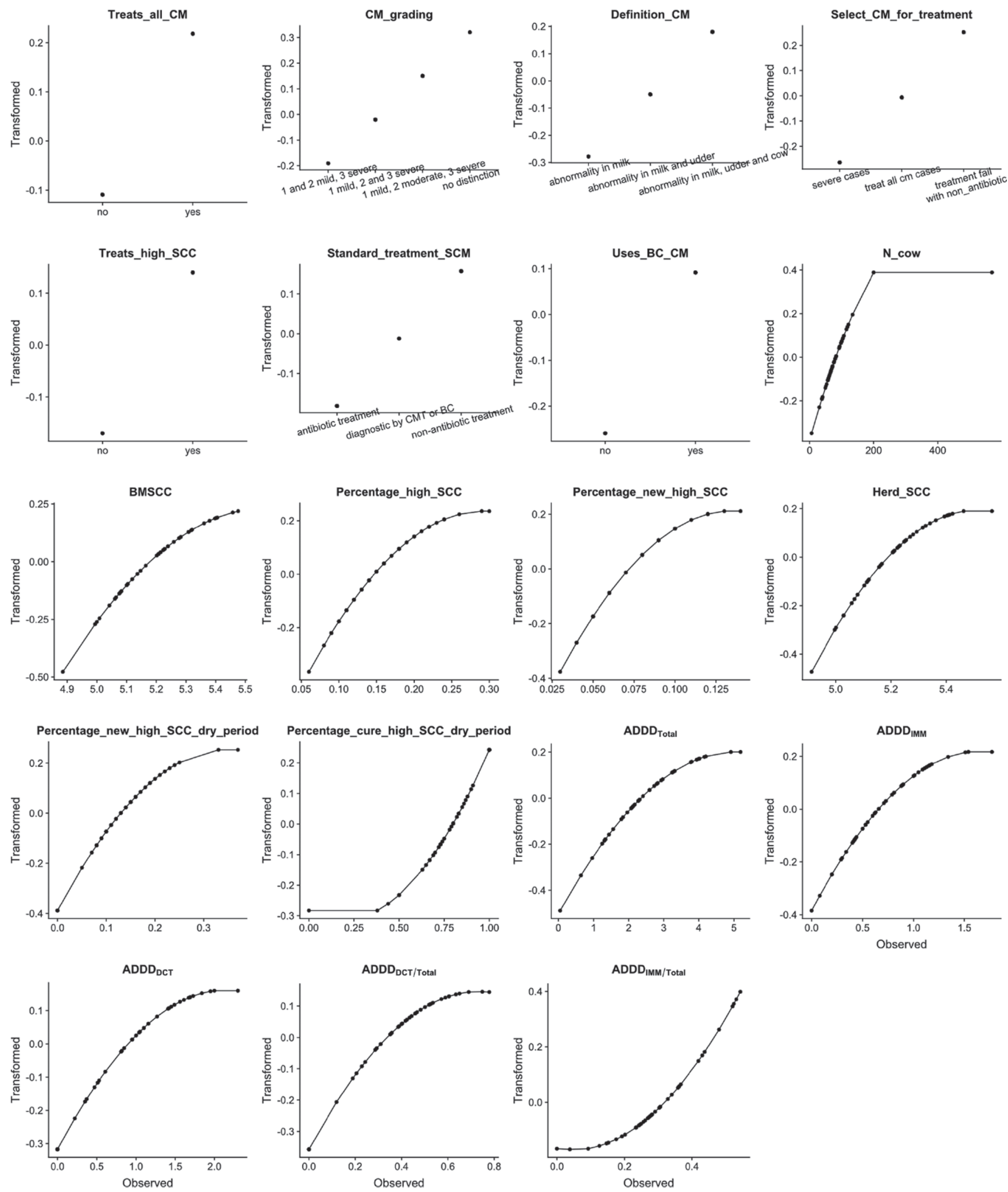

Figure 2. Transformation plots of the variables with variable loadings $>0.30$ or $<-0.30$ used in a 3-dimensional nonlinear principal component analysis of variables from a telephone interview, antimicrobial usage data, and udder health data. Explanations of variable abbreviations can be found in Tables 2 and 3. CMT = California Mastitis Test; $\mathrm{BC}=$ bacteriological culture. 
with an AMS, however, injectable treatments may be more convenient. Still, according to our questionnaire data, most AMS and CMS farmers considered intramammary treatments as the standard for treatment of CM. The Dutch formulary for treatment of mastitis leaves the veterinarian free to decide whether treatment is intramammarily or (also) parenterally. Only 5 farmers added systemic treatments to intramammary treatments in the description of their approach, and these 5 were equally distributed over AMS and CMS farms. This suggests that AMS farmers more often deviate from their primary approach, which may be for reasons of convenience. Another explanation for the lower $\mathrm{ADDD}_{\text {IMM }}$ may be that the AMS herds had a lower incidence rate of $\mathrm{CM}$ and therefore used fewer intramammary treatments. The udder health variables recorded in this study were generally similar for AMS and CMS herds, but the incidence rate of CM was not specifically recorded. Hovinen et al. (2009) reported a lower number of mastitis treatments in herds after transitioning from CMS to AMS. To better understand why AMS farmers use fewer intramammary treatments, it would be necessary to compare the incidence rates of CM between AMS and CMS farms, but such comparisons are greatly hampered by the different diagnostic approaches that can be used on both farm types, which would result in misclassification bias. As Mollenhorst et al. (2012) reported, AMS farmers prefer mastitis alerts that emphasize more severe cases; thus it is likely that the cases found by farmers using AMS are more severe, resulting in more mastitis treatments by injectables.

\section{Approach Toward Mastitis}

Farmers were assured of anonymity to reduce bias toward socially acceptable responses as much as possible. In addition, interviews were performed by a student rather than by an experienced veterinarian or scientist, which likely encouraged farmers to give honest answers. The data from these interviews suggest that AMS farmers in our study have a different concept of CM than the CMS farmers do, and AMS farmers more often mentioned severe clinical signs as characteristics of mastitis. This may be related to the fact that AMS farmers are not manually involved in the milking process and therefore do not fore-strip their cows. Cases of mastitis in an AMS herd are detected through the sensors in the milking machine and checked by the farmers to confirm. However, most AMS farmers prefer sensors to emphasize more severe cases (Mollenhorst et al., 2012) and tend to check only a limited proportion of the alerts (Hogeveen et al., 2013). This process may result in a large proportion of mastitis cases missed, and cases that are found are likely to be more severe on AMS farms. Still, despite this difference, AMS farms could not be distinguished from CMS in the 3-dimensional NLPCA we performed. The AMS herds in our study had lower $\mathrm{ADDD}_{\mathrm{IMM}}$, and the AMS farmers have a different perception of CM, but this does not seem to result in an overall better or worse udder health situation, as is reflected in Table 2. Still, across both farm types, the NLPCA indicated that variables related to SCC were positive on the first PC axis (Figure 1A) and loaded opposite to $\mathrm{ADDD}_{\text {TотAL }}$, showing that greater AMU, in general, was related to better udder health. This may reflect that higher AMU is positively associated with better udder health, or it may show a tendency of farmers who are capable of maintaining good udder health to use antimicrobials more often. However, the second and third PC show that different strategies of using antimicrobials are employed by different groups of farmers. Farms scoring high on PC2 had higher $\mathrm{ADDD}_{\text {TOTAL }}, \mathrm{ADDD}_{\mathrm{DCT}}$, and $\mathrm{ADDD}_{\text {IMM }}$ but loaded relatively high on SCC variables at the same time. It seems that these farms use antimicrobials fairly indiscriminately, resulting in limited improvement of udder health and low cure of high SCC over the dry period. The third PC contrasts farms that use antimicrobials at drying off with farms that use antimicrobials mainly during the lactation (Figure 1B). Farmers who indicated treatment of cases of SCM and of all cases of $\mathrm{CM}$ scored low on this axis. Both percentage of high SCC cases cured during the dry period and percentage of new high SCC cases during the dry period loaded positive on this axis, but the other udder health variables had small loadings on this axis, suggesting that both strategies have a similar effect on overall udder health. Altogether, this analysis suggests that the farmer's attitude toward mastitis strongly influences how much antimicrobials are used but that the usage in itself is not directly linked to the outcome in terms of udder health.

\section{Bacteriological Culture of Milk Samples and AMR of Mastitis-Causing Pathogens}

Although CMS farmers sent in more mastitis samples than the AMS farmers did, the differences in culture results were small, and any differences in distribution of pathogens cultured may well be the result of chance, given the limited sample size of our study. Bacteriological results may be slightly biased by the fact that quarters were selected for sampling by the farmers themselves, based on the criteria they use for CM and SCM in their daily work. We observed a slightly higher percentage of CM cases provided by AMS farmers than by CMS farmers. This might again reflect that AMS farmers considered more severe cases to be CM than 
CMS farmers did, which consequently may have contributed to a lower $\mathrm{ADDD}_{\text {IMM }}$ but a higher $\mathrm{ADDD}_{\text {INJ }}$ for AMS farmers. Nevertheless, it seems clear that the AMR levels of the pathogens grown are generally low. Most resistance was found in staphylococci, and primarily against penicillin $\mathrm{G}$ and pirlimycin, which are antimicrobials frequently used against mastitis in the Netherlands. Penicillin G resistance was higher than the $14 \%$ reported in a previous study for the Netherlands (Thomas et al., 2015). We found no MRSA, but we did identify one NAS isolate resistant to both oxacillin and penicillin G. Streptococcus species were largely free of AMR, in line with the findings of Thomas et al. (2015), but showed some resistance against erythromycin and pirlimycin.

\section{CONCLUSIONS}

This study shows that AMS and CMS farmers use an equivalent total amount of antimicrobials, but AMS farmers tend to use more injectable and fewer intramammary antimicrobial treatments. The signs of CM described by AMS farmers are, on average, more severe than the signs described by CMS farmers. Across AMS and CMS farms, AMU was mainly associated with the farmer's tendency to treat during lactation or at drying off, and differences in this strategy did not correlate with better udder health in general. Larger studies are needed, to better characterize differences between AMS and CMS farmers in how they treat mastitis and to elucidate reasons for higher use of injectable antimicrobials on AMS farms.

\section{ACKNOWLEDGMENTS}

This study is partly sponsored by the China Scholarship Council (Beijing, China), grant number: 201506350111. The authors acknowledge the students and the farmers who participated in this study. The authors have no conflict of interest to declare.

\section{REFERENCES}

Barreiro, J. R., C. R. Ferreira, G. B. Sanvido, M. Kostrzewa, T. Maier, B. Wegemann, V. Böttcher, M. N. Eberlin, and M. V. dos Santos. 2010. Short communication: Identification of subclinical cow mastitis pathogens in milk by matrix-assisted laser desorption/ionization time-of-flight mass spectrometry. J. Dairy Sci. 93:5661-5667. https://doi.org/10.3168/jds.2010-3614.

Biggadike, H. J., I. Ohnstad, R. A. Laven, and J. E. Hillerton. 2002. Evaluation of measurements of the conductivity of quarter milk samples for the early diagnosis of mastitis. Vet. Rec. 150:655-658. https://doi.org/10.1136/vr.150.21.655.

de Haas, Y., W. Ouweltjes, J. ten Napel, J. J. Windig, and G. De Jong. 2008. Alternative somatic cell count traits as mastitis indicators for genetic selection. J. Dairy Sci. 91:2501-2511. https://doi .org/10.3168/jds.2007-0459.
Deng, Z., G. Koop, T. J. G. M. Lam, I. A. van der Lans, J. C. M. Vernooij, and H. Hogeveen. 2019. Farm-level risk factors for bovine mastitis in Dutch automatic milking dairy herds. J. Dairy Sci. 102:4522-4535. https://doi.org/10.3168/jds.2018-15327.

Gonggrijp, M. A., I. M. G. A. Santman-Berends, A. E. Heuvelink, G. J. Buter, G. van Schaik, J. J. Hage, and T. J. G. M. Lam. 2016. Prevalence and risk factors for extended-spectrum $\beta$-lactamaseand AmpC-producing Escherichia coli in dairy farms. J. Dairy Sci. 99:9001-9013. https://doi.org/10.3168/jds.2016-11134.

Hogeveen, H., K. J. Buma, and R. Jorritsma. 2013. Use and interpretation of mastitis alerts by farmers. Pages 313-319 in Proc. 6th European Conference on Precision Livestock Farming. Precision Livestock Farming, Leuven, Belgium.

Hovinen, M., M. D. Rasmussen, and S. Pyörälä. 2009. Udder health of cows changing from tie stalls or free stalls with conventional milking to free stalls with either conventional or automatic milking. J. Dairy Sci. 92:3696-3703. https://doi.org/10.3168/jds.2008-1962.

Jacobs, J. A., and J. M. Siegford. 2012. Invited review: The impact of automatic milking systems on dairy cow management, behavior, health, and welfare. J. Dairy Sci. 95:2227-2247. https://doi.org/ $10.3168 /$ jds.2011-4943.

Kayitsinga, J., R. Schewe, G. Contreras, and R. Erskine. 2017. Antimicrobial treatment of clinical mastitis in the eastern United States: The influence of dairy farmers' mastitis management and treatment behavior and attitudes. J. Dairy Sci. 100:1388-1407. https:/ /doi.org/10.3168/jds.2016-11708.

Kuipers, A., W. J. Koops, and H. Wemmenhove. 2016. Antibiotic use in dairy herds in the Netherlands from 2005 to 2012. J. Dairy Sci. 99:1632-1648. https://doi.org/10.3168/jds.2014-8428.

Lam, T. J. G. M., B. H. P. van den Borne, J. Jansen, K. Huijps, J. C. L. van Veersen, G. van Schaik, and H. Hogeveen. 2013. Improving bovine udder health: A national mastitis control program in the Netherlands. J. Dairy Sci. 96:1301-1311. https://doi.org/10.3168/ jds.2012-5958.

Levy, S. 2014. Reduced antibiotic use in livestock: How Denmark tackled resistance. Environ. Health Perspect. 122:A160-A165. https:// doi.org/10.1289/ehp.122-A160.

Linting, M.. J. J. Meulman, P. J. F. Groenen, and A. J. van der Kooij. 2007. Nonlinear principal components analysis: Introduction and application. Psychol. Methods 12:336-358. https://doi .org/10.1037/1082-989X.12.3.336.

Mair, P., J. De Leeuw, and P. Groenen. 2017. Gifi: Multivariate analysis with optimal scaling. Accessed Nov. 10, 2019. https://rdrr.io/ rforge/Gifi/.

Mathew, A. G., R. Cissell, and S. Liamthong. 2007. Antibiotic resistance in bacteria associated with food animals: A United States perspective of livestock production. Foodborne Pathog. Dis. 4:115133. https://doi.org/10.1089/fpd.2006.0066.

Mitchell, J. M., M. W. Griffiths, S. A. McEwen, W. B. McNab, and A. J. Yee. 1998. Antimicrobial drug residues in milk and meat: Causes, concerns, prevalence, regulations, tests, and test performance. J. Food Prot. 61:742-756. https://doi.org/10.4315/0362 $-028 \mathrm{X}-61.6 .742$.

Mollenhorst, H., L. J. Rijkaart, and H. Hogeveen. 2012. Mastitis alert preferences of farmers milking with automatic milking systems. J. Dairy Sci. 95:2523-2530. https://doi.org/10.3168/jds.2011-4993.

More, S. J., T. A. Clegg, and F. McCoy. 2017. The use of national-level data to describe trends in intramammary antimicrobial usage on Irish dairy farms from 2003 to 2015. J. Dairy Sci. 100:6400-6413. https://doi.org/10.3168/jds.2016-12068.

NMC. 2017. Laboratory Handbook on Bovine Mastitis. Natl. Mastitis Counc., Verona, WI.

Nobrega, D. B., J. De Buck, and H. W. Barkema. 2018. Antimicrobial resistance in non-aureus staphylococci isolated from milk is associated with systemic but not intramammary administration of antimicrobials in dairy cattle. J. Dairy Sci. 101:7425-7436. https:/ /doi.org/10.3168/jds.2018-14540.

Nor, N. M., W. Steeneveld, and H. Hogeveen. 2014. The average culling rate of Dutch dairy herds over the years 2007 to 2010 and its association with herd reproduction, performance and health. J. Dairy Res. 81:1-8. https://doi.org/10.1017/S0022029913000460. 
Pinzón-Sánchez, C., and P. L. Ruegg. 2011. Risk factors associated with short-term post-treatment outcomes of clinical mastitis. J. Dairy Sci. 94:3397-3410. https://doi.org/10.3168/jds.2010-3925.

R Core Team. 2018. R: A language and environment for statistical computing. R Foundation for Statistical Computing, Vienna, Austria. Accessed Aug. 8, 2018. http://www.R-project.org.

Saini, V., J. T. McClure, D. T. Scholl, T. J. DeVries, and H. W. Barkema. 2012. Herd-level association between antimicrobial use and antimicrobial resistance in bovine mastitis Staphylococcus aureus isolates on Canadian dairy farms. J. Dairy Sci. 95:1921-1929. https://doi.org/10.3168/jds.2011-5065.

Scherpenzeel, C. G. M., S. H. W. Tijs, I. E. M. den Uijl, I. M. G. A. Santman-Berends, A. G. J. Velthuis, and T. J. G. M. Lam. 2016. Farmers' attitude toward the introduction of selective dry cow therapy. J. Dairy Sci. 99:8259-8266. https://doi.org/10.3168/ jds.2016-11349.

SDa. 2018. Usage of Antibiotics in Agricultural Livestock in the Netherlands in 2017: Trends and Benchmarking of Livestock Farms and Veterinarians. Accessed Nov. 10, 2019. https://cdn.i-pulse .nl/autoriteitdiergeneesmiddelen/userfiles/Publications/engels-def -rapportage-2017.pdf.

Speksnijder, D. C., D. J. Mevius, C. J. M. Bruschke, and J. A. Wagenaar. 2015. Reduction of veterinary antimicrobial use in the Netherlands: The Dutch success model. Zoonoses Public Health 62(Suppl. 1):79-87. https://doi.org/10.1111/zph.12167.

Steeneveld, W., and H. Hogeveen. 2015. Characterization of Dutch dairy farms using sensor systems for cow management. J. Dairy Sci. 98:709-717. https://doi.org/10.3168/jds.2014-8595.

Steeneveld, W., J. C. M. Vernooij, and H. Hogeveen. 2015. Effect of sensor systems for cow management on milk production, somatic cell count, and reproduction. J. Dairy Sci. 98:3896-3905. https:// doi.org/10.3168/jds.2014-9101.

Tang, K. L., N. P. Caffrey, D. B. Nóbrega, S. C. Cork, P. E. Ronksley, H. W. Barkema, A. J. Polachek, H. Ganshorn, N. Sharma, J. D. Kellner, and W. A. Ghali. 2017. Restricting the use of antibiotics in food-producing animals and its associations with antibiotic resistance in food-producing animals and human beings: A systematic review and meta-analysis. Lancet Planet. Health 1:e316-e327. https://doi.org/10.1016/S2542-5196(17)30141-9.
Thomas, V., A. de Jong, H. Moyaert, S. Simjee, F. El Garch, I. Morrissey, H. Marion, and M. Vallé. 2015. Antimicrobial susceptibility monitoring of mastitis pathogens isolated from acute cases of clinical mastitis in dairy cows across Europe: VetPath results. Int. J. Antimicrob. Agents 46:13-20. https://doi.org/10.1016/j .ijantimicag.2015.03.013.

Van Boeckel, T. P., S. Gandra, A. Ashok, Q. Caudron, B. T. Grenfell, S. A. Levin, and R. Laxminarayan. 2014. Global antibiotic consumption 2000 to 2010: An analysis of national pharmaceutical sales data. Lancet Infect. Dis. 14:742-750. https://doi.org/10 .1016/S1473-3099(14)70780-7.

van der Peet, G., F. Leenstra, I. Vermeij, N. Bondt, L. Puister, and J. van Os. 2018. Feiten en Cijfers over de Nederlandse Veehouderijsectoren 2018. Accessed Nov. 10, 2019. https://edepot.wur.nl/ 464128.

Vanhoudt, A., K. van Hees-Huijps, A. T. M. van Knegsel, O. C. Sampimon, J. C. M. Vernooij, M. Nielen, and T. van Werven. 2018. Effects of reduced intramammary antimicrobial use during the dry period on udder health in Dutch dairy herds. J. Dairy Sci. 101:3248-3260. https://doi.org/10.3168/jds.2017-13555.

Viguier, C., S. Arora, N. Gilmartin, K. Welbeck, and R. O'Kennedy. 2009. Mastitis detection: Current trends and future perspectives. Trends Biotechnol. 27:486-493. https://doi.org/10.1016/j.tibtech 2009.05.004.

Vilar, M. J., M. Hovinen, H. Simojoki, and P. J. Rajala-Schultz. 2018. Short communication: Drying-off practices and use of dry cow therapy in Finnish dairy herds. J. Dairy Sci. 101:7487-7493. https: //doi.org/10.3168/jds.2018-14742.

\section{ORCIDS}

Z. Deng ๑ https://orcid.org/0000-0002-9297-7956

H. Hogeveen $\odot$ https://orcid.org/0000-0002-9443-1412

T. van Werven ( https://orcid.org/0000-0003-2391-0253 